\title{
INVESTIGATION OF Cu ADSORPTION ON THE Si(001) SURFACE USING A CLUSTER MODELS
}

\author{
T. S. Mysakovych \\ Institute for Condensed Matter Physics of the NASU, \\ 1, Svientsitskii St., Lviv, UA-79011, Ukraine \\ mysakovych@icmp.lviv.ua \\ (Received January 18, 2011)
}

\begin{abstract}
Density functional theory calculations have been used to investigate the adsorption of copper atoms on the H-passivated $\mathrm{Si}(001)$ surface. The surface is modeled using the cluster approximation. The plausible sites for the copper adsorption are revealed and the adsorption energy is calculated. The bond lenghts and Mulliken population analysis are reported for all the considered sites of adsorption.
\end{abstract}

PACS number(s): 68.43.-h

\section{INTRODUCTION}

The silicon surface is one of the most extensively studied systems in surface science due to its great technological importance for semiconductor devices. Wet chemical etching of silicon is an important method in the fabrication of micro-electromechanics systems. Many experimental and theoretical works have been done to reveal the structure of the $\mathrm{Si}(001)$ surface, which undergoes surface reconstruction when the surface silicon atoms dimerize to form an energetically more favorable configuration. Generally, it is adopted that these surface dimers are asymmetric, although some ab-initio calculations lead to the conclusion that the symmetric case takes place $[1,2]$. The $\mathrm{Si}$ surface is nearly fully terminated by $\mathrm{Si}-\mathrm{H}$ bonds during wet etching and the hydrogenated Si clusters can also be regarded as a model of porous silicon. The adsorption of hydrogen onto $\mathrm{Si}(001)$ follows various stages, adsorption of a full monolayer leads to the saturated, monohydride surface [3], for a rewiev, see [4].

$\mathrm{Cu}$ has a dramatic impact on the etch rate and the silicon surface morphology. As compared with other metal impurities, copper seems to have a particular preference to adsorb on the H-terminated surface during etching. In [5] the invetigation of a surface morphology, electrophysical characteristics and gas sensitivity of the metalsilicon structures with a surface layer of the porous silicon modified by copper were carried out, such investigations are important for gas sensor applications. There is a limited number of theoretical studies of the interaction of copper and silicon in the presence of hydrogen [6-8]. In this work, we investigate copper adsorption on the hydrogen-terminated silicon surface using cluster model and analyze bond lenght and charge distribution in the system.

\section{METHOD AND RESULTS}

Cluster models are frequently used for studying different aspects of physics and chemistry of surfaces. The clusters $\mathrm{Si}_{9} \mathrm{H}_{12}, \mathrm{Si}_{1} 5 \mathrm{H}_{21}$ are often used as a model of $\mathrm{Si}$ surface $[9,10]$. In our calculations we use hydrogenated cluster with one surface dimer $\mathrm{Si}_{9} \mathrm{H}_{14}$ (see fig. 1). We also considered clusters with two surface dimers $\mathrm{Si}_{15} \mathrm{H}_{20}$ (fig. 2) and $\mathrm{Si}_{21} \mathrm{H}_{28}$ (fig. 3), the first cluster represents the surface in the direction of adjacent dimers and the second cluster is used to imitate the surface in the perpendicular direction (we use different clusters to investigate the plausible sites of $\mathrm{Cu}$ on $\mathrm{Si}$ surface). Initially all Si atoms are located at the bulk lattice sites given by diamond structure with a lattice constant of 5.43 Angstrom. All dangling bonds of the silicons are saturated with hydrogen atoms (the $\mathrm{H}$ atoms are used to terminate the bonds of the Si atoms). The first step in the structure relaxation was to optimize the positions of the terminating hydrogens, with the silicon coordinates kept fixed at their bulk values. In the second step we fixed $\mathrm{Si}$ atoms of the forth layer (and the corresponding $\mathrm{H}$ atoms), we also fixed the positions of the $\mathrm{H}$ atoms of the third and second layers. The positions of the topmost three Si layers and other $\mathrm{H}$ atoms were optimized. The calculations were performed using the Firefly quantum chemical package [11], which is partially based on the GAMESS [12] source code. It should be noted that the basis set used in ab-initio molecular-orbital calculations is a compromise between accuracy and computational cost. We used density functional theory with B3LYP functional and 6- $31 \mathrm{G}^{* *}$ basis set for the hydrogen, silicon and copper atoms. The obtained clusters are shown in Figs. 1, 2, 3.

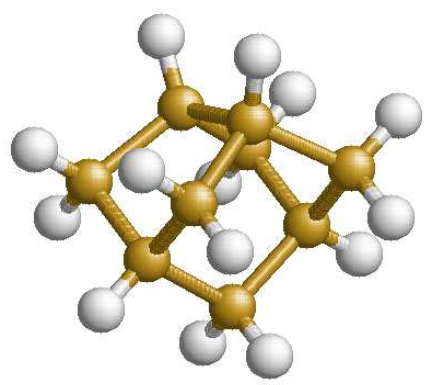

Fig. 1. Cluster $\mathrm{Si}_{9} \mathrm{H}_{14}$. 


\section{T. S. MYSAKOVYCH}

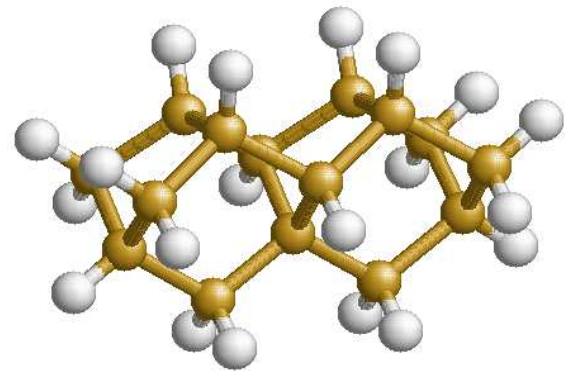

Fig. 2. The $\mathrm{Si}_{15} \mathrm{H}_{20}$ cluster

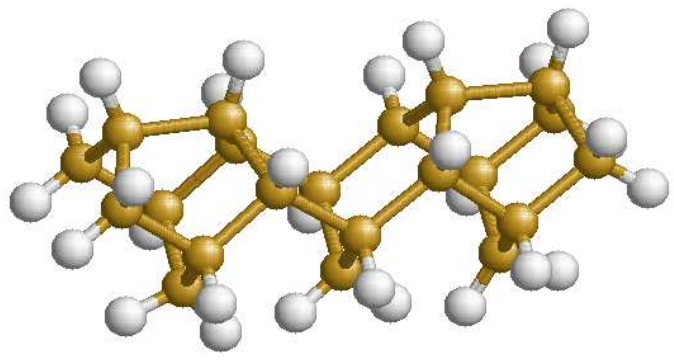

Fig. 3. The $\mathrm{Si}_{21} \mathrm{H}_{28}$ cluster

In the next step we considered the adsorption of an initially neutral copper atom on these clusters. When we investigated the adsorption of copper, the Si atoms and surface hydrogen atoms were allowed to relax, while all other atoms were kept frozen (we also keept frozen the coordinates of the Si atoms of the fourth layer). To examine the stability of adsorption at different sites, we calculate the adsorption energy

$$
E_{a}=E\left(\mathrm{Cu}+\mathrm{Si}_{\text {cluster }}\right)-E(\mathrm{Cu})-E\left(\mathrm{Si}_{\text {cluster }}\right) .
$$

The negative value of the adsorption energy indicates possibilities of adsorption.

In Figs. 4-9 we have shown the possible sites for $\mathrm{Cu}$ adsorption and electron density plots (the latter were obtained using the macmolplt program [13]). In the case A copper adatom has strong bonds with two surface hydrogen atoms and two silicon top layer atoms while in the case of the adsorption at $\mathrm{B}$ and $\mathrm{C}$ sites $\mathrm{Cu}$ forms bonds with silicon atoms.

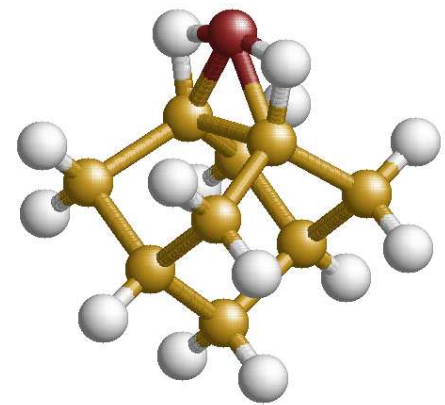

Fig. 4. The $\mathrm{Si}_{9} \mathrm{H}_{14} \mathrm{Cu}$ cluster (adsorption site $\mathrm{A}$ ).
The adsorption energies are as follows

$$
\begin{aligned}
& E_{a}(\mathrm{~A})=-1.76 \mathrm{eV} \\
& E_{a}(\mathrm{~B})=-1.7 \mathrm{eV} \\
& E_{a}(\mathrm{C})=-1.92 \mathrm{eV} .
\end{aligned}
$$

All the found sites are potential sites for $\mathrm{Cu}$ adsorption. Site $\mathrm{C}$ has the lowest adsorption energy. The adsorption site which is similar to our site $\mathrm{C}$ was considered in $[6,7]$ in the framework of the plane-wave implementation of density-functional theory. It was shown that this site has the lowest energy between the adsorption site energies on the surface (this conclusion is similar to our result), but the value of the adsorption energy in [7] was larger $(-3.1 \mathrm{eV}$ in [7] and $-1.92 \mathrm{eV}$ in our work). On the other hand, the ab-initio investigation of the $\mathrm{Cu}$ adsorption on the H-terminated silicon (111) surface [8] revealed that the highest value of the adsorption energy is $-1.44 \mathrm{eV}$ and they did not obtain such large values of adsorption energy as that obtained in $[6,7]$.

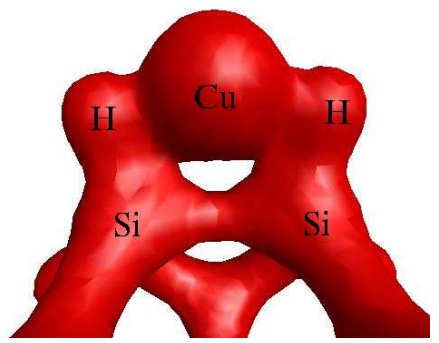

Fig. 5. Electron density (adsorption site A).

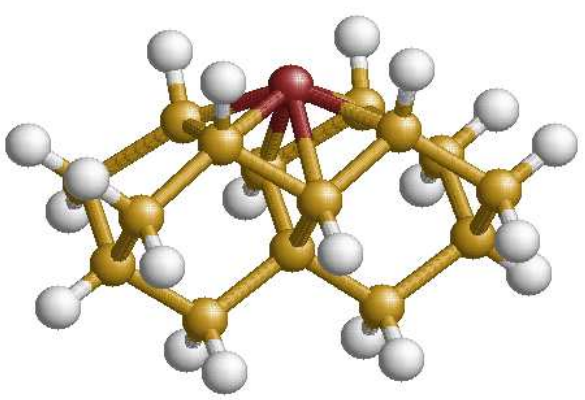

Fig. 6. The $\mathrm{Si}_{15} \mathrm{H}_{20} \mathrm{Cu}$ clusters (adsorption site $\mathrm{B}$ ).

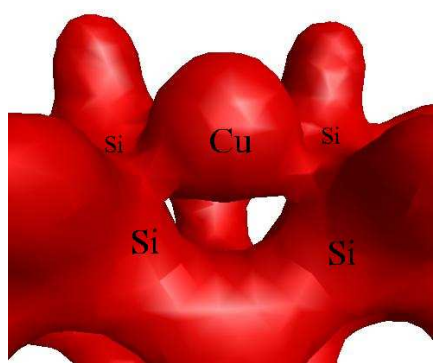

Fig. 7. Electron density (adsorption site B). 
A study of the molecular orbitals shows that a new singly occupied molecular orbital (SOMO) appears (in comparison with Si-clusters without $\mathrm{Cu}$ ), this orbital lies between HOMO (highest occupied molecular orbital) and LUMO (lowest unoccupied molecular orbital) of the initial Si-cluster without $\mathrm{Cu}$.

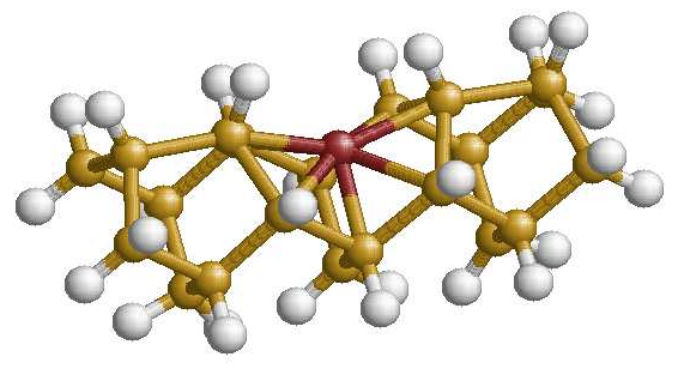

Fig. 8. The $\mathrm{Si}_{21} \mathrm{H}_{28} \mathrm{Cu}$ clusters (adsorption site $\mathrm{C}$ ).

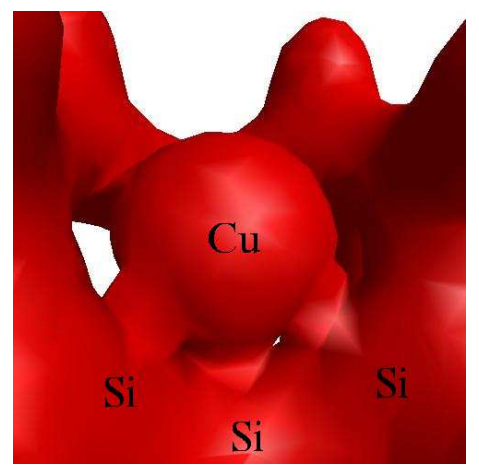

Fig. 9. Electron density (adsorption site C).

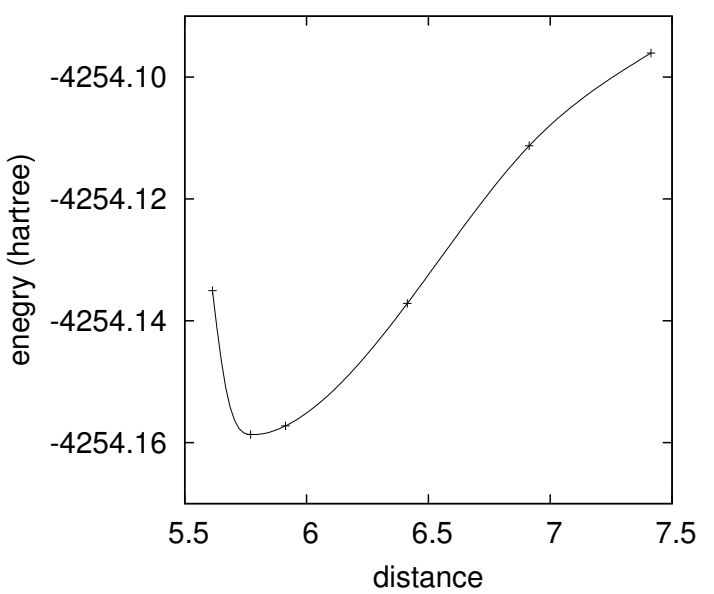

Fig. 10. Energy of the $\mathrm{Si}_{9} \mathrm{H}_{14}+\mathrm{Cu}$ system vs. distance between $\mathrm{Cu}$ and the fourth $\mathrm{Si}$ atom layer.

For all surface sites, the height of the adatom above the Si cluster was varied, the minimum of the system energy yields the adsorption energy. These curves are shown in Figs. $10-12$. The distance in these figures is the distance between the $\mathrm{Cu}$ atom and the fourth layer of Si atoms (as was noted above we fixed the coordinates of the fourth layer $\mathrm{Si}$ atoms). As we can see from these figures, the potential well at the $\mathrm{B}$ and $\mathrm{C}$ sites is wide enough in comparison with the case of the adsorption at the site A. There is no activation energy for the adsorption of copper.

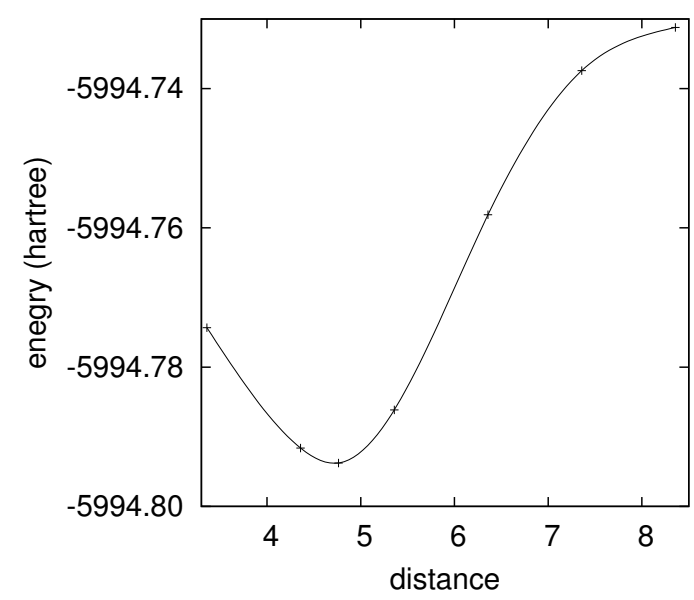

Fig. 11. Energy of the $\mathrm{Si}_{15} \mathrm{H}_{20}+\mathrm{Cu}$ system vs. distance between $\mathrm{Cu}$ and the fourth $\mathrm{Si}$ atom layer.

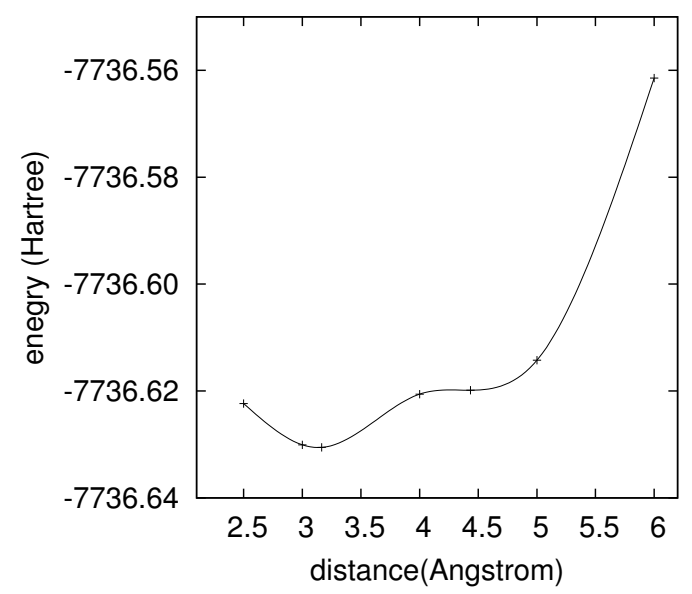

Fig. 12. Energy of the $\mathrm{Si}_{21} \mathrm{H}_{28}+\mathrm{Cu}$ system vs. distance between $\mathrm{Cu}$ and the fourth $\mathrm{Si}$ atom layer.

For all surface sites, the height of the adatom above the $\mathrm{Si}$ cluster was varied, the minimum of the system energy yields the adsorption energy. These curves are shown in Figs. 10,11,12. The distance in these figures is the distance between $\mathrm{Cu}$ atom and the fourth layer of $\mathrm{Si}$ atoms (as was noted above we fixed the coordinates of the fourth layer Si atoms). As we can see from these figures, the potential well at the B and C sites is enough wide in comparison with the case of the adsorption at the site $\mathrm{A}$. There is no activation energy for the adsorption of copper. 


\section{T. S. MYSAKOVYCH}

Table 1 lists the nearest surface neighbor adatom bond lenghts for all plausible sites of adsorption considered in this study. At the adsorption of $\mathrm{Cu}$ some reconstruction of the Si surface takes place. The bond lengh of the dimer gets longer in the cases $\mathrm{B}$ and $\mathrm{C}$ and it gets a little shorter in the case $\mathrm{A}$. We have also analyzed the charge distribution using Mulliken population analysis (see Table 2), we present the charges of the $\mathrm{Si}$ atoms which interact with $\mathrm{Cu}$. In all cases the $\mathrm{Cu}$ atom gained nega- tive charge (in the case A the magnitude of this charge is very small). The surface Si atoms of the first (top) layer gain a positive charge (site $\mathrm{B}$ and $\mathrm{C}$ ), while in the case of the site $\mathrm{A}$ these atoms gain a negative charge (in the last case this negative charge is compensated by the positive charge gained by the second layer atoms). The fourth layer atoms almost do not change their charge in the $\mathrm{A}$ and $\mathrm{B}$ cases.

\begin{tabular}{|c|c|c|c|c|}
\hline Cluster & $\left(\mathrm{Cu}-\mathrm{Si}_{\text {top }}\right)$ & $\left(\mathrm{Cu}-\mathrm{H}_{\text {top }}\right)$ & $\begin{array}{c}\left(\mathrm{Si}_{\text {top }}-\mathrm{Si}_{\text {top }}\right) \\
(\text { dimer })\end{array}$ & $\left(\mathrm{Si}_{\text {top }}-\mathrm{H}_{\text {top }}\right)$ \\
\hline \hline $\mathrm{Si}_{9} \mathrm{H}_{14}+\mathrm{Cu}$ & 2.284 & 1.624 & $2.484[2.494]$ & $1.654[1.495]$ \\
\hline $\mathrm{Si}_{15} \mathrm{H}_{20}+\mathrm{Cu}$ & 2.458 & 2.786 & $2.513[2.485]$ & $1.498[1.495]$ \\
\hline $\mathrm{Si}_{21} \mathrm{H}_{28}+\mathrm{Cu}$ & 2.812 & 3.1 & $2.515[2.479]$ & $1.492[1.495]$ \\
\hline
\end{tabular}

Table 1. Bond lenght (Angstroms). In square brackets bond lenghts for free clusters are presented.

\begin{tabular}{|c|c|c|}
\hline Cluster & Atom & Charge \\
\hline \multirow{6}{*}{$\mathrm{Si}_{9} \mathrm{H}_{14}+\mathrm{Cu}$} & $\mathrm{Cu}$ & $-0.027[0]$ \\
\hline & $\mathrm{Si}_{\text {top }}$ & $-0.07[-0.017]$ \\
\hline & $\mathrm{H}_{\text {top }}$ & $-0.08[-0.03]$ \\
\hline & $\mathrm{Si}_{\text {second layer }}$ & $0.169[0.128]$ \\
\hline & $\mathrm{Si}_{\text {third layer }}$ & $-0.005[-0.012]$ \\
\hline & $\mathrm{Si}_{\text {fourth layer }}$ & $0.108[0.103]$ \\
\hline \multirow{6}{*}{$\mathrm{Si}_{15} \mathrm{H}_{20}+\mathrm{Cu}$} & $\mathrm{Cu}$ & $-0.187[0]$ \\
\hline & $\mathrm{Si}_{\text {top }}$ & $0.043[0.007]$ \\
\hline & $\mathrm{H}_{\text {top }}$ & $-0.033[-0.035]$ \\
\hline & $\mathrm{Si}_{\text {second layer }}$ & $0.07[0.074]$ \\
\hline & $\mathrm{Si}_{\text {third layer }}$ & $-0.074[-0.095]$ \\
\hline & $\mathrm{Si}_{\text {fourth layer }}$ & $0.131[0.13]$ \\
\hline \multirow{6}{*}{$\mathrm{Si}_{21} \mathrm{H}_{28}+\mathrm{Cu}$} & $\mathrm{Cu}$ & $-0.216[0]$ \\
\hline & $\mathrm{Si}_{\text {top }}$ & $0.053[0.017]$ \\
\hline & $\mathrm{H}_{\text {top }}$ & $-0.025[-0.037]$ \\
\hline & $\mathrm{Si}_{\text {second layer }}$ & $0.052[0.045]$ \\
\hline & $\mathrm{Si}_{\text {third layer }}$ & $0.075[0.084]$ \\
\hline & $S i_{\text {fourth layer }}$ & $0.174[0.13]$ \\
\hline
\end{tabular}

Table 2. Atomic charge distribution. In square brackets atomic charges for free clusters are presented.

\section{CONCLUSIONS}

The effects of $\mathrm{Cu}$ adsorption on the $\mathrm{Si}(001)$ surface have been investigated using density functional theory and cluster approach. It was observed that for the three sites of high symmetry considered, all sites are candidates for adsorption of copper. Mulliken population analysis indicates that in all cases the $\mathrm{Cu}$ adatom gained nega- tive charge. Basically the first or the second Si layer loses charge. In general, we have shown that copper can adsorb strongly to the H-terminated silicon surface and that the adsorption energy is dependent on the local bonding environment.

\section{Acknowledgement}

This work was supported by the National Academy of Sciences of Ukraine, Project number 35/10-H. 
[1] B. Paulus, Surf. Sci. 408, 195 (1998).

[2] Y. Jung, Y. Shao, M. S. Gordon, D. J. Doren, M. HeadGordon, J. Chem. Phys. 119, 10917 (2003).

[3] Z. Jing, J. L. Whitten, Phys. Rev. B 46, 9544 (1992).

[4] W. Brenig, E. Pehlke, Prog. Surf. Sci. 83, 263 (2008).

[5] T. I. Gorbanyuk, A. A. Evtukh, V. G. Litovchenko, V. S. Solntsev, Physica E 38, 211 (2007).

[6] A. Rodriguez-Prieto, D. R. Bowler, Phys. Rev. B 80, 155426 (2009).

[7] A. Rodriguez-Prieto, D. R. Bowler, Phys. Rev. B 81, 129902(E) (2010).
[8] A.S. Foster, M. A. Gosalvez, T. Hynninen, R. M. Nieminen, K. Sato, Phys. Rev. B 76, 075315 (2007).

[9] E. Penev, P. Kratzer, M. Scheffler, J. Chem. Phys. 110, 3986 (1999).

[10] S. B. Healy, C. Filippi, P. Kratzer, E. Penev, M. Scheffler, Phys. Rev. Lett. 87, 016105 (2001).

[11] A. A. Granovsky, Firefly version 7.1.G, http://classic. chem.msu.su/gran/firefly/index.html

[12] M. W. Schmidt et al., J. Comput. Chem. 14, 1347 (1993).

[13] B. M. Bode, M. S. Gordon, J. Mol. Graph. Model. 16, 133 (1998).

\title{
ДОСЛІДЖЕННЯ АДСОРБЩІї Сu НА ПОВЕРХНІ $\mathrm{Si(001)} \mathrm{ЗА} \mathrm{ДОПОМОГОЮ}$ КЛАСТЕРНИХ МОДЕЛЕЙ
}

\author{
Т. С. Мисакович \\ Інститут фізики конденсованих систем НАН України, \\ вул. Свенціцького, 1, Лъвів, UА-79011, Україна
}

За допомогою розрахунків методом функціонала густини досліджено адсорбцію міді на поверхні $\mathrm{Si}(001)$, покритій воднем. Поверхня моделюється за допомогою кластерів. Виявлено можливі місця адсорбції міді та розраховано енергї̈ адсорбції. Наведено довжини зв'язків та заряди для всіх знайдених місць адсорбції. 